\title{
Corpo e afeto nas culturas juvenis.
}

João Batista de Menezes Bittencourt ${ }^{1}$

Resumo: $\mathrm{O}$ artigo busca pistas para a compreensão da relação entre corpo e afeto nas experiências das culturas juvenis, à partir de alguns apontamentos sobre as práticas adotadas pelos adeptos do estilo de vida straighetdge - jovens que utilizam o corpo como lócus privilegiado para a exposição de seus posicionamentos e visões de mundo. Incorporando a concepção espinosista de afeto ao cabedal teórico-metodológico que constitui uma antropologia do corpo, podemos dizer que o papel do pesquisador seria o de mapear, ou melhor, de cartografar os afetos que atravessam os corpos, o que transforma seu trabalho numa espécie de etologia social.

Palavras-chave: Corpo, Afeto, Culturas Juvenis.

Abstract: The article seeks clues to understanding the relationship between body and affect the experiences of youth cultures, based on some notes on the practices adopted by supporters of lifestyle straighetdge - young people who use the body as a privileged locus for the exhibition of their mates and worldviews. Incorporating the Spinozist conception of affection to the upper theoretical and methodological what constitutes a a anthropology of the body, we can say that the role of the researcher was to map, or rather to map the affections crossing bodies, which makes your job a kind of social ethology.

Keywords: Body, Affection, Youth Cultures

Falar sobre juventude contemporânea é também falar sobre movimento. Não me refiro a movimentos sociais propriamente ditos, ou seja, os diversos grupos instituídos que os jovens se engajam para fazer política na esfera pública, mas sim a própria ação sugerida pela palavra movimento, que advém do latim movere, deslocar, colocar em movimento. Grande parte dos comentários feitos a respeito dos jovens possuem como referência um certo mal estar diante da sua condição móvel, dizem alguns: "são inconstantes", "são apressados", "são impacientes", "vivem em transição", "são nômades". A maioria das expressões transparecem a idéia de que esses agentes não conseguem se fixar em nenhum ponto, por estarem

${ }^{1}$ Doutor em Ciências Sociais e Professor do Programa de Pós Graduação em Sociologia da Universidade Federal de Alagoas. E-mail: joaobitt.cs@gmail.com

Latitude, vol. 6, n¹, pp.25-36, 2012

DOI: https://doi.org/10.28998/2179-5428.20120103 


\section{Corpo e afeto nas culturas juvenis.}

sempre se deslocando; argumento que também serve para reforçar uma acentuada desvalorização dos estilos de vida jovens, que passam a ser percebidos como "modismos passageiros", em oposição as "identidades adultas", consideradas mais resistentes às mudanças.

Apesar de discordar da idéia de que os jovens são "essencialmente nômades", e os adultos "essencialmente sedentários", acredito que os primeiros possuem uma certa vantagem sobre os segundos no quesito "mobilidade", e que está relacionada a uma certa "disposição" (que aqui não possui conotação biológica) para a experimentação, para o encontro com o inusitado. Os conceitos de "espaço estriado" e "espaço liso" desenvolvidos pelos pensadores Gilles Deleuze \& Felix Guattari, apresentados no livro Mil Platôs Vol. 5, nos ajudam a compreender melhor essa "disposição" que eu considerei ter maior incidência entre os jovens. Inspirado por Deleuze \& Guattari, podemos sugerir que os jovens estariam mais próximos do espaço liso, ou seja, do espaço da invenção, do nomadismo; do performativo. Nesse espaço os pontos estão subordinados ao trajeto. Já os adultos, pressionados pelos grandes agenciamentos sociais, teriam como principal referencia o espaço estriado, o espaço da disciplina e do controle. Já nesse espaço, as linhas e os trajetos tem tendência a ficar subordinados aos pontos.

É preciso abrir um parênteses para esclarecer o que estou definindo como "mobilidade", que aqui não possui relação (ao menos diretamente) com deslocamento territorial em sua concepção clássica, ou seja, o ato de circular despreocupadamente entre os distintos pontos da cidade bastante comum entre os bandos jovens. Ela se refere de maneira mais específica aos deslocamentos que se processam nas cartografias juvenis; permitindo que jovens transitem entre territórios subjetivos, sem o compromisso de filiação com qualquer um deles. É nas culturas juvenis, onde podemos perceber de maneira mais intensa essas transformações, em virtude do seu caráter eminentemente performativo e de seu forte direcionamento para o presente. Para refletir sobre essas mutações no plano subjetivo das culturas juvenis, proponho que voltemos nossa atenção para a dimensão do afeto, ou melhor, para a influência dessa matéria intensiva sobre os corpos dos jovens.

O primeiro exercício que deve ser feito é se perguntar sobre a origem do afeto. Para tal feito, devemos recorrer ao filósofo Bento (Baruch, Benedito) de Espinosa, e principalmente a leitura materialista que o filósofo Gilles Deleuze (2002) faz de seus textos, aproximando-o de Nietzsche. Como é sabido, Espinosa é um filósofo de tradição cartesiana, porém, seu racionalismo se expressa mais nos seus posicionamentos críticos a um pensamento considerado "supersticioso" - que segundo o autor é uma paixão negativa nascida da imaginação - do que pela adoção de sistema de explicação metafísico. Deleuze se interessa pela tese materialista de Espinosa, que pode ser definida pela expressão "o que pode o corpo?". Tagarelamos sobre as mil formas de mover o corpo e de dominar suas 
João Batista de Menezes Bittencourt

paixões mas não sabemos do que é capaz um corpo. Dessa forma, Espinosa toma o corpo como modelo, não para mostrar sua preeminência sobre o espírito, mas sim para indicar que ambos possuem uma conexão intrínseca, o que inverteu o princípio que instituía a Moral no domínio das paixões pela consciência. Era impossível pensar num paralelismo entre corpo e alma, pois dizia-se que a alma não atua se o corpo não padecer, e vice-versa. De acordo com Espinosa, quando um corpo encontra outro, e este se compõe com o nosso, ou quando uma idéia se encontra com nossa alma e com ela se compõe, sentimos alegria. Inversamente, quando um corpo ou idéia ameaçam nossa coerência sentimos tristeza. Em poucas palavras somos um grau de potência definidos pela capacidade de afetar e ser afetado, e tudo depende de uma questão de experimentação. Selecionar a matéria que aumenta nossa potencia de agir ou por outro lado excluir aquela que diminui nossa potencia, é um aprendizado.

Incorporando essa concepção de afeto ao cabedal teórico-metodológico que constitui uma sociologia ou antropologia do corpo, podemos dizer que o papel do pesquisador seria o de mapear, ou melhor, de cartografar os afetos que atravessam os corpos - o que transforma seu trabalho numa espécie de etologia social. A concepção de corpo desenvolvida por Espinosa é definida por uma multidão de outros corpos, nos remetendo a idéia de que este, pode ser afetado de diferentes maneiras por uma variedade de corpos, logo, os corpos são aquilo que seus afetos indicam. Assim, o cientista social, de maneira semelhante ao etólogo, voltaria sua atenção para a "matéria prima afetiva", ou seja, a energia mobilizadora responsável pela produção e transformação dos corpos.

Podemos passar agora ao objetivo do artigo, que é compreender quais os afetos estão em jogo na produção da experiência corporal nas chamadas "culturas juvenis" em nossos dias, possuindo como referência as práticas ascéticas encabeçadas pelos/as adeptos/as do estilo de vida straightedge, jovens que utilizam o corpo como lócus privilegiado para a exposição de seus posicionamentos e visões de mundo.

A escolha pelo estilo de vida straightedge se deu justamente pelo fato dos jovens atualizarem através de determinadas práticas, uma experiência corporal paradoxal, pois ao mesmo tempo que se adéquam a um rigoroso regime disciplinar pautado por abstinência de substâncias consideradas por eles prejudiciais ao corpo e a mente, em um outro momento subvertem os limites impostos ao corpo através da relação que mantêm com a música punk/hardcore. Levando em consideração a máxima espinosana de que os corpos são aquilo que seus afetos indicam, entendemos que essas distintas experiências resultam de "bons" e "maus encontros" que acometem esses jovens cotidianamente. Não se trata de construir uma polarização afirmando que eles vivenciam um "mau encontro" quando se relacionam com determinados códigos de conduta, e por outro lado, têm um "bom encontro" quando livre destes, se entregam a uma 


\section{Corpo e afeto nas culturas juvenis.}

performance extasiante num show de música hardcore. É importante salientar que em ambos os casos é possível haver bons e maus encontros, como veremos à seguir.

\section{Disciplina}

Analisada de uma forma superficial, a filosofia straightedge é geralmente associada a uma espécie de "pastoral da carne", onde os jovens necessariamente precisam fazer morrer seus desejos para se adequarem a um conjunto de normas específicas, a uma moral de grupo. São muitos os comentários depreciativos direcionados ao jovem straightedge: dogmático, radical, moralista, reacionário, porém, estes só servem para aumentar ainda mais a curiosidade em torno das práticas que compõem esse estilo de vida. O suposto incômodo provocado pela adoção de práticas ascéticas por segmentos juvenis, pode estar relacionado a uma naturalização da juventude como uma fase de descobertas, de experiências intensas e desordenadoras, o que desemboca consequentemente na "naturalização" - não somente no discurso do senso comum, como também na fala de muitos pesquisadores - da relação entre juventude e drogas². Desse modo,

${ }^{2}$ Estudos sobre delinqüência e errância como características que são próprias da condição juvenil reforçam essa argumentação. Em nosso imaginário social, a juventude está relacionada a um período de transição, de experimentações e descobertas, o que torna o jovem um navegante sem bússola. E esse imaginário, assim como as significações que o compõem, ajudou a fomentar não somente o discurso do senso comum, como também o discurso da ciência. Até hoje nos deparamos com pesquisas de apelo biologizante e psicologizante que tem por objetivo encontrar alternativas de diminuição da errância juvenil, tida como patológica, passível de cura. Estudos clássicos no campo da sociologia da juventude, reproduzem, sobre alguns aspectos, a noção de que na adolescência os jovens são acometidos de uma crise, que é tida como característica marcante desse período intermediário. O texto de René Fau (1968) "Características gerais do grupo durante a adolescência" é bastante emblemático nesse sentido. Apesar de Fau discordar da idéia de que a rebeldia e a busca pela liberdade é algo inerente ao adolescente, o autor indica que a adaptação do adolescente a um grupo funciona como apoio durante a crise que ele atravessa. Outro trabalho clássico nessa perspectiva, é o estudo sobre a participação de jovens em gangues de Frederik Thrasher, chamado The Gang, de 1927. Desde o lançamento desse livro, viram-se inúmeros trabalhos publicados sobre juventude tendo sempre como enfoque a marginalidade e a delinquência. A insistência em relacionar o desvio a essa fase da vida em específico, foi o fio condutor daquilo que mais adiante viria a ser chamado de deviance theory ou "teoria do desvio comportamental". Um importante passo para a desmistificação da relação inerente entre juventude e desvio, foi dado em 1963 pelo 
quando pensamos na afinidade existente entre juventude e ascetismo, logo somos reportados aos grupos que estão de alguma forma conectados ao universo religioso nas suas mais diversas expressividades, e que fazem dessa prática um exercício de assujeitamento a alguma divindade. A imagem do jovem asceta como um indivíduo coberto de tatuagens, piercings e alargadores, e que dança ao som da musica hardcore, certamente não está entre as representações mais comuns elencadas por estudiosos, o que exige de nós pesquisadores um pouco mais de "imaginação socioantropológica" para tratar desse fenômeno contemporâneo.

Podemos até afirmar que para muitos (dentro e fora da academia) é bem mais compreensivo que um jovem faça uso de substâncias entorpecentes do que o contrário. Existe um espanto generalizado diante dos straightedges, como se eles estivessem de alguma maneira ferindo o estatuto do jovem contemporâneo que se assenta sobre a máxima "viver cada dia como se fosse o último". Punks que não usam drogas? "Tem alguma coisa estranha nesses jovens" - dizem alguns.

Diante dessas considerações, torna-se fundamental estar atento a ambivalência que percorre as práticas corporais e discursivas assumidas por estes jovens. É possível vermos na idéia de "disciplina" dois movimentos distintos, pois se esta por um lado possui uma conotação negativa, no que se refere a um excessivo controle do corpo, por outro funciona como exercício à favor da liberdade. Desse modo, a disciplina ganha uma nova roupagem na fala dos straightedges, ela é a possibilidade de se manterem sóbrios, questionadores, responsáveis por suas próprias vidas:

"Eu achava interessante como o straightedge parecia ter a percepção de que parece haver uma contradição entre você pregar e tentar aplicar na sua vida uma ideologia de liberdade individual, e não conseguir exercer essa liberdade porque você é viciado numa substância, entendeu? Porque você acaba tendo um monte de comportamentos condicionados por causa dessas substâncias mais ainda do que você já é condicionado e também por outros fatores..." (P, 30 anos).

sociólogo Howard Becker com o lançamento do livro Outsiders: studies in sociology of deviance. Esse trabalho tinha como premissa fundante a idéia de que o desvio, enquanto fenômeno social, está intimamente relacionado com o processo de criação de regras, comum à todos os grupos sociais. 


\section{Corpo e afeto nas culturas juvenis.}

Na fala acima, o entrevistado salienta que a filosofia straightedge oferece uma percepção de que é contraditório ir em busca de uma suposta liberdade individual construída pela idéia de que tudo é permitido, e não refletir sobre o fato de que a ingestão de certas substâncias coloca obstáculos a essa mesma liberdade. Para muito dos entrevistados, existe uma espécie de "glamorização" do consumo de drogas, como se elas tornassem o jovem ou a jovem mais atraente, mais confiante, e que este(a), geralmente não se posiciona para refletir sobre esse discurso. É possível perceber na fala desse jovem uma concepção de "liberdade" que está atrelada a possibilidade de gerir sua vida sem a interferência de certos condicionamentos que viriam a impedi-los de serem "mais autênticos", ou "honestos consigo mesmo", porém, isso não significa afirmar que os jovens straightedges desfrutam necessariamente de maior autonomia do que os jovens que têm seu estado de consciência alterado pelo uso de drogas. É importante destacar que em alguns casos, a captura pela identidade straightedge se exerce com grande intensidade, gerando uma espécie de "automatismo" subjetivo entre os adeptos, minimizando a possibilidade de diálogo entre as formações territoriais instituídas e as formações intimas desterritorilizantes. Desse modo, a disciplina deixa de ser uma prática que permite aos jovens uma elaboração singular de si e passa a ser encarada como uma "moral da renúncia". Essa relação de "subserviência" as regras do grupo se expressa de maneira mais incisiva nos recém-adesistas. Jovens nessa condição se destacam em relação aos demais em virtude de um comprometimento explícito com a filosofia de vida, que pode ser traduzido por uma crença exagerada nos valores que a fundamentam. A disciplina, dessa maneira, se torna, um atributo que garantiria aos recém-adeptos, a possibilidade de reconhecimento entre os straightedges "experientes", ao menos sob a perspectiva daqueles.

A partir desses dois exemplos temos acesso não apenas a duas formas distintas de apropriação discursiva ou pontos de vista, mas, principalmente, a dois modos distintos de relação entre os jovens e o respectivo código de conduta; encontro de corpos e idéias com forças exteriores que podem aumentar ou diminuir a força da ação e do pensamento. A seguir, mostraremos com os "bons" e "maus" encontros produzem distintas experiências corporais entre os jovens durante a performance nos shows de música hardcore.

\section{Performance hardcore}

Partindo da premissa de que todos nós somos um grau de potência definidos pela capacidade de afetar e ser afetado, resolvi "interpretar" a performance dos jovens nos shows de hardcore dentro de uma perspectiva diferente 
daquela desenvolvida pela chamada antropologia da performance ${ }^{3}$. Mesmo considerando extremamente pertinentes as análises empreendidas por esse campo de pesquisa, é impossível não reconhecermos o fato de que em todas elas há uma tentativa de interpretação dos sentidos, que são atribuídos aos gestos mediante uma leitura do conteúdo das expressividades. Mesmo que alguns autores indiquem que a performance na contemporaneidade deixou de ser regida pelas representações coletivas, a intencionalidade das ações ainda é o paradigma reinante, ou seja, a preocupação continua sendo com o conteúdo.

${ }^{3} \mathrm{O}$ enfoque dado a questão da performance em meu trabalho se afasta um pouco das análises desenvolvidas pela antropologia da performance em sua concepção mais tradicional, à saber: os trabalhos desenvolvidos por Turner (1974), Geertz (1978, 2001), Taussig (1993), Schechner $(1985,1988)$, entre outros. A perspectiva apresentada por esses autores consiste numa tentativa de interpretação da realidade social a partir dos eventos rituais e do teatro, algo que se assemelha as análises desenvolvidas por E. Goffman no início do século XX, cujo objetivo era compreender as ações empreendidas pelos indivíduos a partir da dramatização que se encenava no cotidiano através dos ritos de interação. Podemos dizer que a diferença entre o trabalho de Goffman - representante do interacionismo simbólico - e os outros desenvolvidos posteriormente, a partir da década de 60, estar nesses reconhecerem o elemento da afetividade, expandindo dessa maneira o campo de possibilidades interpretativas. Victor Turner pode ser considerado o principal nome da chamada "antropologia da performance", principalmente depois de seu trabalho com os Ndembu da África Central, cujo foco de análise foram seus os rituais. A influência do folclorista Van Gennep é latente nos escritos de Turner. A noção de drama social, expressão pela qual o antropólogo definiu os rituais Ndembu, teve como inspiração os estudos sobre ritos de passagem de Gennep, que tinha como fonte de inspiração o teatro grego. Podemos dividir o trabalho de Turner em duas partes que se complementam: uma que compreende a análise dos ritos de passagem entre os Ndembu, apresentada no livro $O$ Processo Ritual; e outra que compreende seus estudos nas sociedades complexas, onde focou atividades como o teatro, a dança e a música. No livro From Ritual to Theatre, o autor se aproxima de Geertz ao afirmar que a ação ritual, "é uma história em que o grupo narra a si mesmo". A diferença está na maneira como a ação ritual é analisada. Se nas chamadas "sociedades simples", essas ações (ritos de passagem, dramas) eram mediadas pela esfera do sagrado, no sentido dessas práticas estarem relacionadas ao funcionamento de uma ordem social, nas "sociedades complexas" essas ações estão relacionadas a interesses particulares diversos, como por exemplo, a busca pelo prazer sensorial da dança.

Latitude, vol. 6, n¹, pp.25-36, 2012. 


\section{Corpo e afeto nas culturas juvenis.}

Um detalhe que precisa ser salientado, pois salta aos olhos na performance realizadas pelos/as jovens nesses eventos, é a maneira como estes/as conseguem expor seus corpos às diferentes formas de "agressão", parecendo não se importarem com a dor. A partir de uma sociogênese da violência nos moldes de Norbert Elias (1992), é possível afirmar que a performance hardcore é uma prática semelhante a algumas formas de desporto como o futebol, o boxe, ou o Rugbi. Todas estas têm em comum o ingrediente da "agressividade", porém, são traduzidas como expressões de uma violência física socialmente aceita. De acordo com o sociólogo, a violência e a agressividade são sentimentos que acompanham a humanidade desde sempre, mas o processo civilizador que se estendeu sobre o ocidente atuou na contenção dessas pulsões, instituindo rituais que permitiram a canalização da "violência má" para uma "violência boa". Do ponto de vista da sociologia, que sempre privilegiou o estudo dos conteúdos, entendo que a análise de Elias é extremamente pertinente para nos ajudar a compreender uma história das práticas corporais no ocidente - sendo possível, por exemplo, identificarmos a "violência" presente nos gestos encenados na dança como formas privilegiadas para a liberação de uma energia instintiva que ficara resguardada - contudo, penso que para além do corpo formado por órgãos, tecidos e pulsões, existe outro corpo que se virtualiza enquanto potência nessa performance; corpo enquanto produção de afetos, corpo enquanto possibilidade constante de devir. Assim, a performance hardcore é aquilo que seus afetos indicam, pode ser multiplicidade pura e sem medida, irrupção do efêmero, potência da metamorfose, ou então "fascismo da matilha", quando ocorre o estriamento da performance; gerando codificação do corpo e instauração dos binarismos hierarquizantes.

No momento da dança, as diferenças são completamente apagadas, morrese o gênero, morre-se as idades, e o que passa a existir são apenas corpos em ebulição agenciados pelos afetos que estão dispersos naquele ambiente (música, calor, cheiros). Porém, como sabemos, os afetos são de natureza ambígua, existem aqueles que aumentam nossa potência de agir e de pensar, permitindo deviresmoleculares (devir-animal, devir-criança, devir-mulher) e outros que, por outro lado, impedem a expansão desses devires, molarizando a performance, construindo identidades, hierarquias, fazendo emergir o corpo blindado; uma microcristalização fascizante (Guattari, 1981) produzida por um agenciamento que atravessa o desejo e altera a cartografia dos/das jovens que participam da performance hardcore. Essa cristalização subjetiva não pode se confundir com o machismo ou com o sexismo, que alguns sociólogos e militantes atribuem a uma produção genuinamente masculina, resultante da manutenção de uma estrutura sócio-histórica que produz uma clivagem entre homens e mulheres. No ato da performance, tanto os garotos como as garotas estão propensas a dar vazão ao corpo blindado, que se expressa numa acentuada apologia da violência e a manutenção de posturas sectárias em relação às demais garotas. Os relatos de 
agressão sofrida durante a performance é bastante comum entre as garotas: olho roxo, costelas fraturadas, sangramentos, desmaios em shows; descrições que são apresentadas muitas vezes de forma exagerada e aparecem como signos de poder. É como se o número de experiências dolorosas, que se traduzem muitas vezes em hematomas visivelmente expostos em seus corpos, se convertessem em medalhas conquistadas em uma batalha, garantindo-lhes status diferenciado, ajudando a traçar uma hierarquia entre as "meninas de atitudes" e as "medrosas".

O Corpo blindado ao qual nos referimos é uma das possibilidades de "mau encontro" que pode ocorrer durante os shows, porém, agenciado com Deleuze \& Guattari podemos dizer que o mesmo jovem que se reterritorializa a partir de uma cristalização fascizante, pode se desterritorializar num devir-animal ou devir-criança; devires-minoritários produzidos através do bom encontro de corpos com afetos alegres, o que reforça ainda mais a tese espinosana de que ninguém sabe o que pode um corpo. Qualquer explicação homogeneizadora baseada em rotulações apriorísticas é insuficiente para compreender os processos desterritorializantes e reterritorializantes produzidos na subjetividade dos jovens em questão.

É no ato performático onde podemos perceber de forma mais intensa a produção desses devires. É como se a música destituísse momentaneamente os códigos sociais pelos quais se reconhecem (idade, gênero, grupo) permitindo a intrusão de novos vetores de subjetivação. Para alguns straightedges/devotos de krishna, a interpretação do "sair de si" experimentado durante a performance hardcore ganha conotação espiritual, momento de transcendência onde o jovem se desconecta do "eu" racional para se conectar à divindade.

“Eu, quando começo a tocar... Putz, eu até já chorei tocando cara. Uma vez eu tive a impressão de ter visto krishna quando estava tocando. Eu estava super concentrado. E eu quando estou tocando, eu fico uma outra pessoa no palco, não sei se você já viu...eu acabo aumentando minha percepção sobre muitas outras coisas quando estou tocando. É uma tríade entre a gente, hardcore e krishna. No palco eu sou um devoto com uma guitarra na mão. (J,22 anos)

Penso, que mais interessante do que o conteúdo discursivo apresentado na fala deste jovem, é a descrição da experiência in acto, ou seja, não interessa se o jovem realmente viu krishna e muito menos se eu acredito na veracidade dos fatos. A questão que se coloca, e que sob meu ponto de vista é mais importante compreende o indizível da experiência, o arrebatamento provocado pelo êxtase e 


\section{Corpo e afeto nas culturas juvenis.}

que pode levá-los as mais diversas interpretações. Viveiros de Castro (2002) nos oferece uma chave interessante quando discorre sobre o estatuto de certas afirmações fornecidas por seus interlocutores indígenas. Ao ser questionado por uma pesquisadora se ele acreditava de fato nestes quando afirmavam que os pecaris (porcos) são humanos, ele respondeu:

“... o que o antropólogo deve perguntar não é 'se acredita ou não' que os pecaris sejam humanos, mas o que uma idéia como essa lhe ensina sobre as noções indígenas de humanidade e 'pecaritude', o que uma idéia como essa, note-se, ensina-lhe sobre essas noções e outras coisas: sobre as relações entre ele e seu interlocutor, as situações em que tal 'enunciado' é produzido espontaneamente, os gêneros da fala e os jogos de linguagem em que ele cabe, etc. (pg.136)

Apesar de não estarmos nos referindo a sociedade indígenas, penso que as observações de Viveiros de Castro pode nos ajudar a compreender o que não está implícito na afirmação do jovem no tocante ao suposto encontro com Krishna. Devemos nos perguntar: para que serve esta idéia? Ou melhor, o que ela nos diz sobre a experiência vivenciada por este jovem? Quando ele afirma ter visto Krishna, não está apenas indicando que teve acesso a uma experiência "desordenadora" quando estava no palco empunhando sua guitarra, mas também está nos dizendo algo sobre a sua condição de devoto, sobre a sua condição de músico, sobre o momento em que esta experiência foi possível, sobre sua relação com o hardcore, enfim, sobre os agenciamentos que o permitiram entrar em contato com este outro agenciamento (krishna). O sentido não pode se esgotar no enunciado, devemos nos perguntar sobre os fios da trama que permitiram sua composição.

A partir da experiência descrita pelo jovem straightedge, é possível vislumbrar a idéia de que os bons encontros que ocorrem durante a performance hardcore, advêm justamente da experiência arrebatadora do êxtase, responsável pela desestabilização das cartografias e conseqüentemente das possíveis cristalizações identitárias que podem vir a se tornarem fascizantes.

Desse modo, concluímos que para compreender as distintas experiências corporais vivenciadas por esses jovens no ato da performance é fundamental nos atermos a força mobilizadora dos afetos, ou seja, a possibilidade de pensar um corpo virtual que se atualiza nos gestos efusivos e descompassados expressos no 
mosh pitt. O momento da festa, do êxtase coletivo, permite a "soltura das amarras", fazendo com que os nós que prendem os indivíduos às identidades fechadas sejam desfeitos momentaneamente, permitindo aos mesmos a experimentação intensa da matéria afetiva que os circundam.

\section{Referências bibliográficas}

ATKINSON, Michael. (2006). "Straightedge bodies and civilizing processes". In: Body \& Society. Sage Publications (London, Thousand Oaks and New Delhi), Vol. 12(1): p.69-95.

BECKER, H. S. (1991). Outsiders: studies in the sociology of deviance. New York: Free Press.

BITTENCOURT, J.B.M. (2008). Mosh não é coisa de menina!: uma reflexão sobre as desigualdades entre os gêneros nos shows de música hardcore na cidade de São Paulo. Texto apresentado no Simpósio Internacional Fazendo Gênero 8. Florianópolis.

BLANCHOT, M. (1969). L'entretien infini. Paris: Gallimard.

DELEUZE, G. \& GUATTARI, F. (1997). Mil Platôs Vol. 4, São Paulo: Editora 34.

DELEUZE, G. \& GUATTARI, F. (2004). O Anti-Édipo: capitalismo e esquizofrenia. Lisboa: Assírio \& Alvim.

DELEUZE, G. Espinosa. Filosofia prática. São Paulo: Escuta, 2002

DELEUZE, G. (2007). Francis Bacon: Lógica da sensação. Rio de Janeiro: Jorge Zahar Editor.

DIÓGENES, Glória. (2003). Itinerários de corpos juvenis: o tatame, o jogo e o baile. São Paulo: Annablume.

GEERTZ, C. (1978). A interpretação das culturas. Rio de Janeiro: Jorge Zahar.

GOFFMAN, E. (1985). A representação do Eu na vida cotidiana. Petrópolis: Vozes.

GUMBRECHT, Hans. (1998). "O Campo não hermenêutico ou a materialidade da comunicação". In: Corpo e Forma - Ensaios para uma critica não hermenêutica. Rio de Janeiro: Eduerj.

ELIAS, Norbert. (1992). A busca da excitação. Lisboa: Difel.

FAU, Renè. "Caracteristicas gerais do grupo durante a adolescência". In: BRITTO, S. (1968). Sociologia da Juventude III - A vida coletiva juvenil. Rio de Janeiro: Jorge Zahar Editor.

FAVRET-SAADA, Jeanne. (2005). "Ser afetado". In: Cadernos de Campo - Revista dos alunos de pós graduação em Antropologia Social da USP, n. 13, Ano 14, p. 155-161.

\footnotetext{
${ }^{4}$ Espaço onde é realizado a performance hardcore.
} 


\section{Corpo e afeto nas culturas juvenis.}

FOUCAULT, Michel. (1984). A História da sexualidade 2 - Os usos dos prazeres. Rio de Janeiro: Graal.

FREUD, S. (2006 [1921]). Psicologia das Massas e análise do ego. Rio de Janeiro: Imago. GOLDMAN, Marcio. (2003). Os tambores dos mortos e os tambores dos vivos. Etnografia, antropologia e política em Ilhéus, Bahia. Rev. Antropol., São Paulo, v. 46, n. 2.

GUATTARI, Félix. (1981). Revolução Molecular: pulsações políticas do desejo. São Paulo: Brasiliense.

GUATTARI, F. \& ROLNIK, S. (2005). Micropolítica: cartografias do desejo. Petrópolis, RJ: Editora Vozes.

GUMBRECHT, Hans. (1998). "O Campo não hermenêutico ou a materialidade da comunicação". In: Corpo e Forma - Ensaios para uma critica não hermenêutica. Rio de Janeiro: Eduerj.

PAIS, Machado. "Buscas de si: identidades e expressividades juvenis". In: ALMEIDA, Maria Isabel Mendes de. \& EUGÊNIO, Fernanda. (2006). Culturas Jovens: novos mapas do afeto. Rio de Janeiro: Jorge Zahar Editor.

ROLNIK, Suely. (2007). Cartografia Sentimental: transformações contemporâneas do desejo. Porto Alegre: Editora Sulina.

SCHECHNER, R. (1988). Performance Theory. New York: Routledge.

TAUSSIG, M. (1993). Xamanismo, colonialismo e o homem selvagem: um estudo sobre o terror e a cura. São Paulo: Paz \& Terra.

TURNER, V. (1974). O Processo ritual: estrutura e antiestrutura. Petrópolis: Vozes.

VIVEIROS DE CASTRO, E. (2002). O nativo relativo. In: Mana 8 (1), pp. 113-148.

ZOURABICHVILI, F. (2004). O Vocabulário de Deleuze. Rio de Janeiro: IC. (Versão eletrônica). 